\title{
Effect of Electronic Prescribing Strategies on Medication Error and Harm in Hospital: a Systematic Review and Meta-analysis
}

\author{
Nadia Roumeliotis, MDCM, MSc ${ }^{1,2}$, Jonathan Sniderman, $M D C M^{7}$, \\ Thomasin Adams-Webber ${ }^{3}$, Newton Addo, MD', Vijay Anand, MD ${ }^{5}$, \\ Paula Rochon, MD, MPH', Anna Taddio, PhD ${ }^{2}$, and Christopher Parshuram, MB.ChB, \\ D.Phil. ${ }^{1,2}$
}

\begin{abstract}
'Department of Critical Care Medicine, The Hospital for Sick Children, Toronto, ON, Canada; ${ }^{2}$ Child Health Evaluative Sciences, and Center for Safety Research, SickKids Research Institute, Toronto, ON, Canada; ${ }^{3}$ Library \& Archives Services, The Hospital for Sick Children, Toronto, ON, Canada; ${ }^{4}$ Division of Clinical Pharmacology, Department of Medicine, UCSF, San Francisco, CA, USA; ${ }^{5}$ Department of Pediatrics, Stollery Children's Hospital, Edmonton, AB, Canada; 'Women's College Research Institute, Women's College Hospital, Toronto, ON, Canada.
\end{abstract}

BACKGROUND: Computerized physician order entry and clinical decision support systems are electronic prescribing strategies that are increasingly used to improve patient safety. Previous reviews show limited effect on patient outcomes. Our objective was to assess the impact of electronic prescribing strategies on medication errors and patient harm in hospitalized patients.

METHODS: MEDLINE, EMBASE, CENTRAL, and CINAHL were searched from January 2007 to January 2018. We included prospective studies that compared hospital-based electronic prescribing strategies with control, and reported on medication error or patient harm. Data were abstracted by two reviewers and pooled using random effects model. Study quality was assessed using the Effective Practice and Organisation of Care and evidence quality was assessed using Grading of Recommendations Assessment, Development, and Evaluation.

RESULTS:Thirty-eight studies were included; comprised of 11 randomized control trials and 27 non-randomized interventional studies. Electronic prescribing strategies reduced medication errors (RR 0.24 (95\% CI 0.13, 0.46), $\left.I^{2} 98 \%, n=11\right)$ and dosing errors (RR 0.17 (95\% CI 0.08, 0.38), $I^{2} 96 \%, n=9$ ), with both risk ratios significantly affected by advancing year of publication. There was a significant effect of electronic prescribing strategies on adverse drug events (ADEs) (RR 0.52 (95\% CI 0.40, 0.68), $I^{2} 0 \%, n=2$ ), but not on preventable ADEs (RR 0.55 (95\% CI $\left.0.30,1.01), I^{2} 78 \%, n=3\right)$, hypoglycemia (RR 1.03 (95\% CI 0.62-1.70), $I^{2} 28 \%, n=7$ ), length of stay (MD $\left.-0.18(95 \%-1.42,1.05), I^{2} 94 \%, n=7\right)$, or mortality (RR 0.97 (95\% CI $\left.0.79,1.19), I^{2} 74 \%, n=9\right)$. The quality of evidence was rated very low.

Prior Presentations The abstract of this manuscript was presented at the Canadian Critical Care Forum in Toronto, in October 2018.

Electronic supplementary material The online version of this article (https://doi.org/10.1007/s11606-019-05236-8) contains supplementary material, which is available to authorized users.

Received February 12, 2019

Revised May 2, 2019

Accepted July 16, 2019

Published online August 8, 2019
DISCUSSION: Electronic prescribing strategies decrease medication errors and adverse drug events, but had no effect on other patient outcomes. Conservative interpretations of these findings are supported by significant heterogeneity and the preponderance of low-quality studies.

KEY WORDS: electronic prescribing; CPOE; CDSS; medication error; preventable adverse drug events.

J Gen Intern Med 34(10):2210-23

DOI: $10.1007 / \mathrm{s} 11606-019-05236-8$

(C) Society of General Internal Medicine 2019

\section{INTRODUCTION}

Information technology has a central role in twenty-first century healthcare. ${ }^{1}$ Electronic medical records support the implementation of computerized physician order entry and clinical decision support systems that are increasingly used with the intent of making prescribing safer. ${ }^{2,3}$ Computerized physician order entry enables order entry, and clinical decision support systems matches patient-specific data with a computerized knowledge base to generate patient-specific recommendations. 4

Over the past decade, information technology and design of computerized order entry and clinical decision support systems have evolved considerably. ${ }^{5}$ Although computerized clinical decision support systems may function independently to assist in drug-related recommendations, newer systems are integrated with computerized physician order entry to aid in weight- and age-based dosing calculation, renal dosing adjustment, screening for drug-drug interactions, administration scheduling, and therapeutic monitoring. ${ }^{2,6,7}$

Previous systematic reviews on electronic prescribing found patient outcomes were infrequently reported r $^{2,7-11}$ and the few studies suggesting benefit of computerized order entry and clinical decision support systems on prescribing error and adverse drug events were of very low-quality, ${ }^{12-16}$ with very few randomized trials. ${ }^{13,17}$ 
Given the increased potential of newer electronic prescribing systems, and their widespread adoption, re-evaluating their effect on patient-relevant outcomes is necessary. We therefore sought to evaluate the impact of newer electronic prescribing strategies, given their lack of evidence on patient safety. The objective of this study was to assess the effect of electronic prescribing strategies on medication errors and patient outcomes.

\section{METHODS}

\section{Study Design}

We conducted a systematic review evaluating the impact of electronic prescribing strategies on medication errors and patient outcomes in hospitals. The review was conducted according to the PRISMA guidelines ${ }^{18}$ (Supplement Table 1) and was prospectively registered (PROSPERO No. CRD42017055663). ${ }^{19}$

\section{Study Eligibility}

We searched for eligible full-text studies published in English from January 1, 2007, to January 1, 2018, that were randomized studies, or prospective non-randomized interventional study designs. Included studies reported on patients in hospitals, in emergency departments, and in long-term care facilities. Eligible interventions were an electronic prescribing strategy, and these were compared with a control without electronic prescribing support. An electronic prescribing strategy was defined as a computerized clinical decision support system, or a computerized physician order entry with or without an embedded clinical decision support system. Reported outcomes had to include at least one of medication error or patient harm outcome.

We excluded studies that were retrospective or ambispective; compared two electronic prescribing strategies; involved multicomponent interventions (training on error reduction, teaching, prescribing reminders, reorganization); included outpatients/ambulatory clinics; and evaluated interventions where applications did not use patientspecific data and where outcomes were limited to administrative process.

\section{Study Outcomes}

The outcomes were medication error and patient harm. We defined medication error as any error in the process of ordering, transcribing, dispensing, administering, and monitoring of medications. ${ }^{15}$ Dosing error was evaluated as a type of medication error.

The patient outcomes included harm and potential harm to the patient. These were the following: (1) adverse drug events (ADEs) and preventable ADEs, (2) a change in patient symptomatology, (3) receipt of inappropriate therapy and time to therapy, (4) clinical effect of therapy, (5) duration of therapy, (6) length of stay, and (7) death. ${ }^{15}$ Harmful or unintended effects of the intervention were reported in each study.

\section{Study Search and Selection}

The search was conducted in MEDLINE (Ovid), EMBASE (Ovid), Cochrane CENTRAL (Ovid), and CINAHL (EBSCO) (TA-W) in February 2018. Search terms included database subject headings and text words for the following: Clinical Decision Support System, Computerized Physician Order Entry, hospital information system, electronic prescribing, computer assisted drug therapy, cohort, and clinical trial. Further adverse event-related keyword search included the following: safety, drug error, prescription errors, dosing error, medication error, and sentinel event (Supplement Methods 1). Additional articles were obtained by screening bibliographic references of included articles, PubMed-related articles, and related systematic reviews. Conference abstracts were not included in the study selection. All citations were imported into EndNote. ${ }^{20}$ Two reviewers (NR, JS) independently evaluated the eligibility of the studies identified in the search. Disagreements were resolved by consensus between reviewers, or by a third reviewer (CP). Where data from a trial were distributed in more than one publication, the principal publication was selected unless it was prior to inclusion date, in which case the later article was chosen.

\section{Data Abstraction and Quality}

All study data was abstracted independently by two reviewers (NR, JS). For each included study, we abstracted study characteristics, country of origin, study design, setting, patient population, characteristics of the electronic prescribing strategy, study period, and outcomes. Interventions were categorized as stand-alone Clinical Decision Support Systems (CDSS) or Computerized Physician Order Entry (CPOE). CPOE functionality was further defined as without CDSS, embedded with limited CDSS (dosing limits and allergy), or advanced CDSS (decision support for weight-based dosing, renal dosing, or drugdrug interactions).

Randomized and non-randomized studies were evaluated for risk of bias using the Effective Practice and Organisation of Care tool from the Cochrane Collaboration; grading each category as "Low," "Unclear," or "High" Risk of Bias. ${ }^{21}$ The quality of evidence for each outcome was assessed across studies by design using the Grades of Recommendation Assessment, Development and Evaluation (GRADE), with randomized controlled trials starting at high quality and nonrandomized prospective studies starting at low quality. ${ }^{22}$ GRADE Evidence Profile and Summary of Findings tables were created with GRADEpro. ${ }^{23}$

We sought contact with authors if study eligibility was unclear, or to complete and clarify missing data for included studies (Fig. 1). 


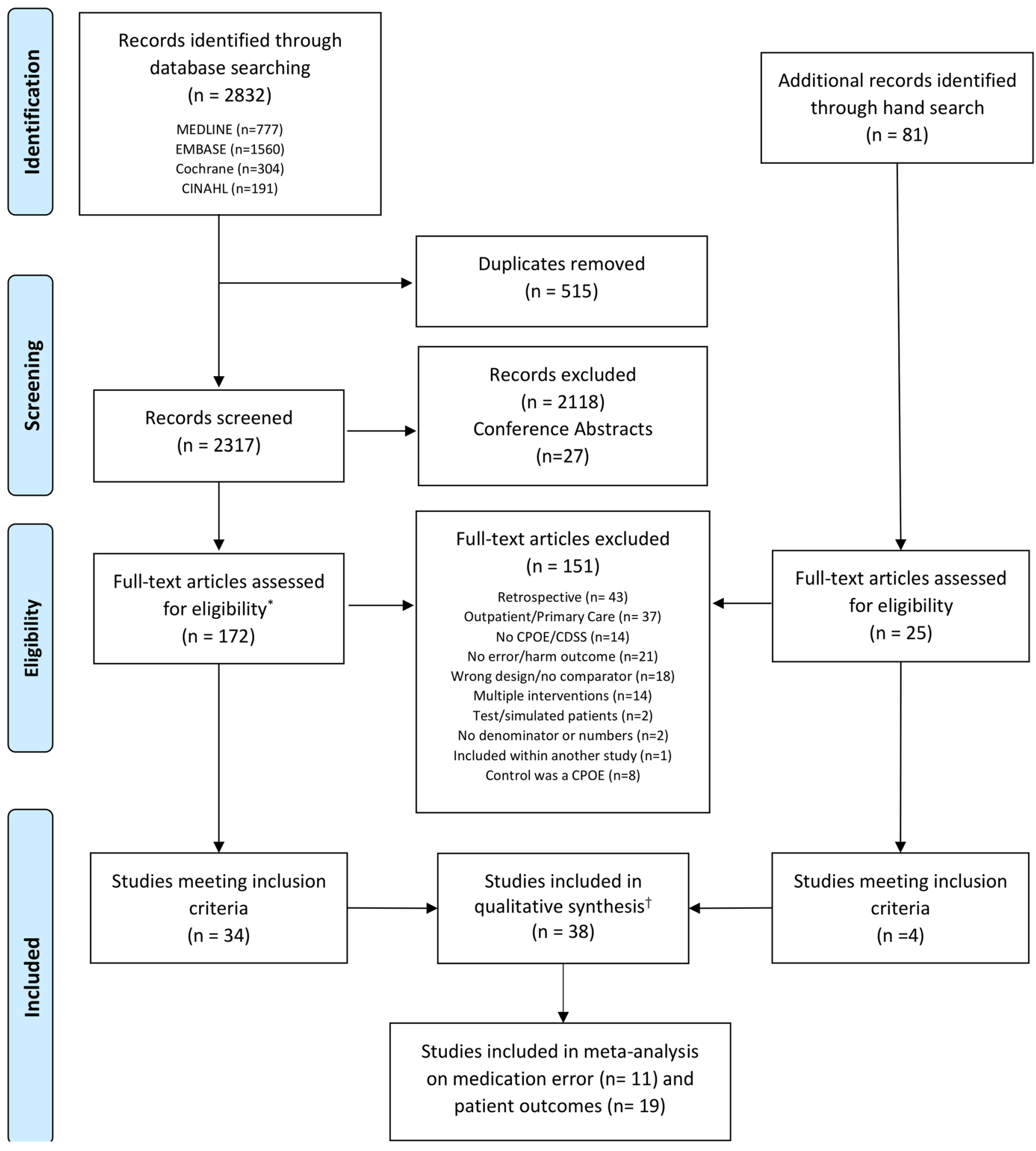

Figure 1 PRISMA study flow diagram. CPOE, computerized physician order entry; CDSS, clinical decision support system. *Ten of 14 authors contacted to confirm study eligibility. If author was not reached, and study eligibility remained unclear, study was excluded. ${ }^{\dagger}$ Two of 5 authors contacted clarified data for quantitative analysis.

\section{Data Management and Analysis}

Studies were described by study design, by outcome, and by study population. Cohens' kappa was used to quantify reviewer agreement for study inclusion. Patient outcomes were summarized using descriptive measures. Due to multiple outcomes, effects were classified according to statistical significance $(p<0.05$ or $95 \%$ confidence interval not including 1).

Medication errors were abstracted as number of medication errors per number of drug prescriptions; however, if errors were reported in proportions, they were converted to absolute 
numbers. Where conversion to absolute numbers was not possible, the study was not included in meta-analysis. ADEs or preventable ADEs were reported as the number of events per total number of patients. Where rates were provided in events per 1000 patient-days, the event rate pre- and postintervention was multiplied by the number of patient-days, and divided by 1000 . This was done when the number of admissions and patient-days was known in both intervention periods. ${ }^{24}$ In non-randomized studies, when two or more time periods were evaluated after an intervention, the last intervention period was compared with their control and included in the quantitative analysis.

Forest plots were used to illustrate the findings of a quantitative analysis when 3 or more studies reported the same outcome, and calculated the relative risk (RR) or mean difference (MD) with 95\% confidence interval. A random effects model was used for all meta-analyses, subtotalled by study design where appropriate. Subtotals were not combined if outcome definition differed, or if a study with 2 intervention groups was included in a subgroup. Meta-regression by year of publication was conducted when the number of studies was sufficient. We used $I^{2}$ to measure heterogeneity across studies and funnel plots with Egger tests to evaluate for publication bias. Forest and funnel plots were created with Review Manager $^{25}$ which were then imported into GRADEpro. Egger tests and meta-regression with bubble plots were performed in RStudio. $^{26}$

\section{RESULTS}

\section{Study Selection}

The review yielded 2832 citations from which 172 full-text articles were reviewed and 34 were included. Hand search of bibliographic review led to a further 25 full-text reviews and four additional included studies, resulting in 38 included studies (Fig. 1). The inter-rater agreement for inclusion of studies from full-text article review was good, with Cohen's kappa 0.67 initially and 0.93 after discussion between reviewers.

\section{Description of Studies}

The 38 included studies were from 12 countries; 33 studies reported on 51,894 patients and five studies described only the number of prescriptions, admissions, or patient-days. The hospital settings included the intensive care unit, wards, emergency department, and operating room (Table 1).

\section{Design}

Eleven $(29 \%)$ randomized controlled trials were included, all of which reported on patient outcomes and none on medication error (Table 1). The units of randomization were wards $(n=1),{ }^{35}$ providers $(n=1),{ }^{33}$ and patients $(n=9) .{ }^{27-32,34,36,37}$ The $27(71 \%)$ non-randomized interventional studies included
23 controlled before-after studies, two interrupted time series, ${ }^{24,40}$ and two interventional cohorts. ${ }^{51,53}$

\section{Methodological Quality Assessment}

The randomized controlled trials (RCTs) included in the study had low or unclear risk of bias (Supplement Table 2). Quality assessment of the included non-randomized studies varied from high to low risk of bias. Studies were heterogeneous with regard to study quality and risk of bias for each outcome (Supplement Table 3).

\section{Interventions}

The electronic prescribing strategies included 24 (63\%) standalone clinical decision support systems and 14 (37\%) computerized physician order entry systems, of which eight had advanced decision support built within them, ${ }^{24,51,55,59-63}$ three had limited decision support, ${ }^{40,52,57}$ two had no decision support, ${ }^{46,50}$ and one did not specify. ${ }^{47}$

Of the stand-alone decision support systems, nine (38\%) evaluated single drug dosing adjustment for insulin $(n=8)^{28-}$ 34,36 and mycophenolate mofetil $(n=1)^{27}$; eight $(33 \%)$ involved surveillance/treatment of infection, ${ }^{44}$ including pneumonia management, ${ }^{56}$ adherence to guidelines for antibiotic therapy, ${ }^{54}$ empiric antibiotic choice, ${ }^{35,38,43}$ empiric antibiotics for surgery ${ }^{45}$ or antibiotic adjustment ${ }^{53}$; and seven $(29 \%)$ were for post-operative nausea and vomiting, ${ }^{48,58}$ rehydration for children, ${ }^{37}$ dose adjustment for renally cleared drugs,${ }^{42}$ drug-drug interactions, ${ }^{41}$ pain control,${ }^{39}$ and medication reconciliation. ${ }^{49}$

The advanced decision support systems within the computerized order entry included tools for detecting drug-drug interactions, ${ }^{51,59}$ pediatric weight-based dosing, ${ }^{24,60-63}$ and specialized chemotherapy ordering. ${ }^{55}$ Given that the majority of computerized order entry systems had a decision support system of some form built within them, they were regarded as a single category for analyses.

\section{Outcomes Evaluated}

Thirteen (34\%) studies reported on medication error (0 RCTs), $29(76 \%)$ reported on a patient harm outcome (11 RCTs), and 3 (8\%) reported both $(0 \mathrm{RCTs}) .{ }^{24,40,59}$ Table 2 summarizes the studies showing improvement in the outcomes (medication error and patient harm outcomes) according to the electronic intervention type.

\section{Medication Errors}

The definitions of medication error in the studies included incomplete prescriptions, prescription correction, dose frequency error, error due to drug-drug interactions, transcription error, and errors in dispensing, administration, and monitoring (Fig. 2a). Ten of 13 (77\%) studies demonstrated a reduction in overall medication error rate (0 RCTs). Two (67\%) of the 3 studies not showing a difference in medication error rates were 


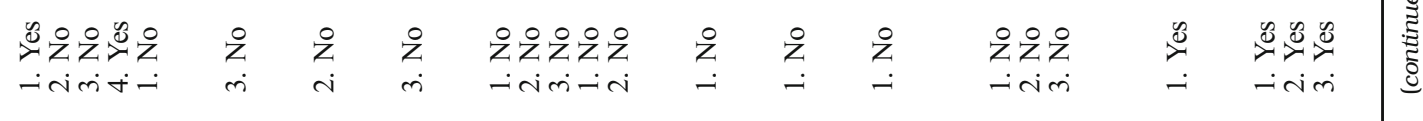

$\begin{array}{lllllll} & & \\ & & \\ 0\end{array}$

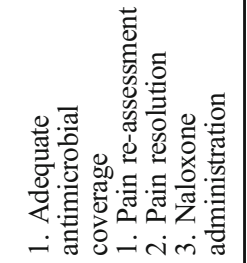

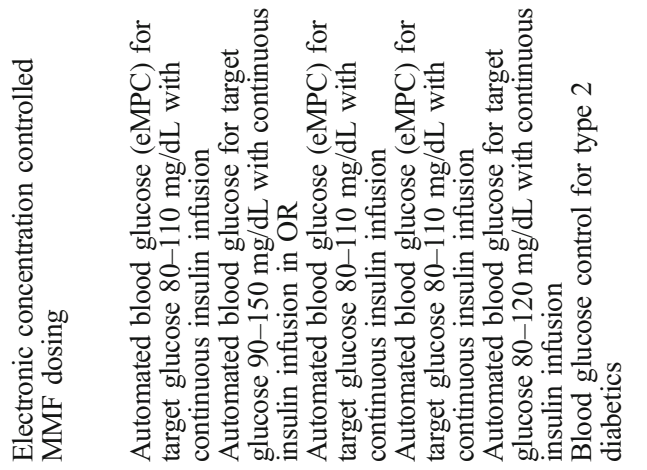
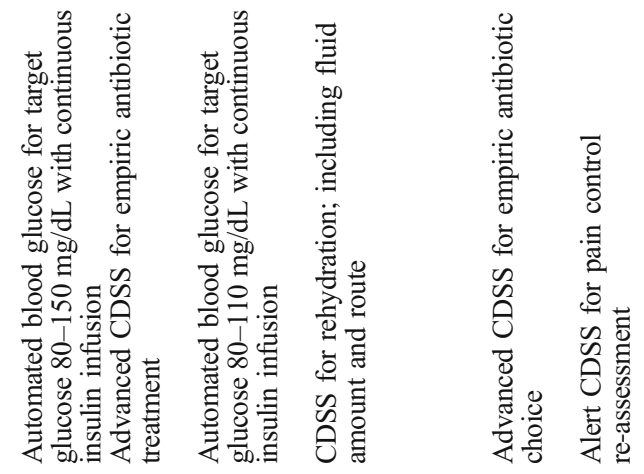

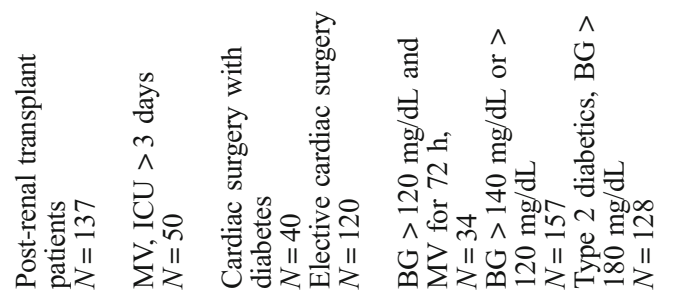

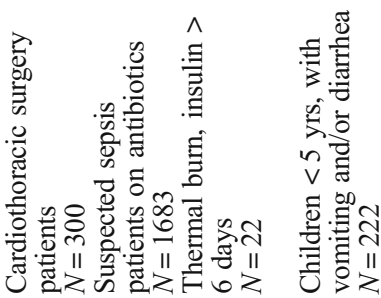

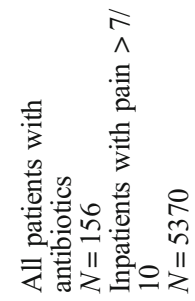

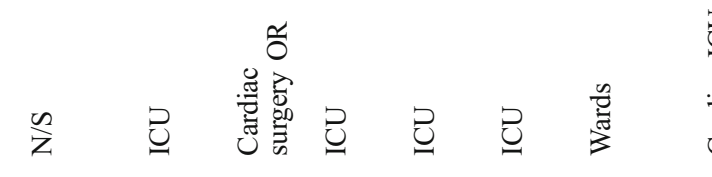

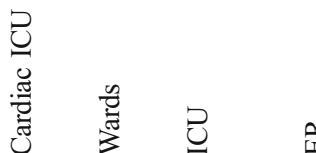

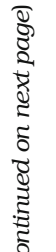

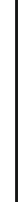




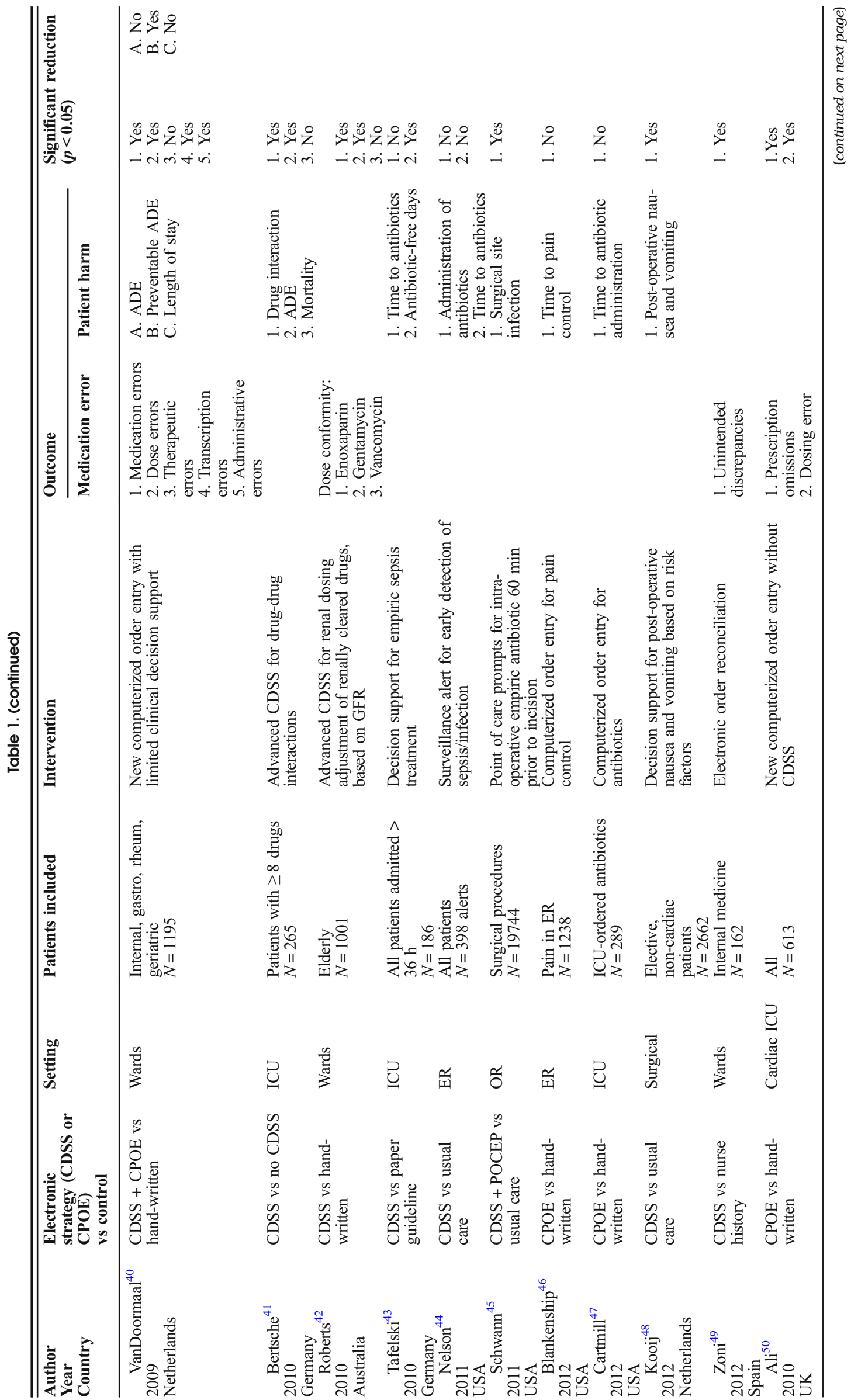




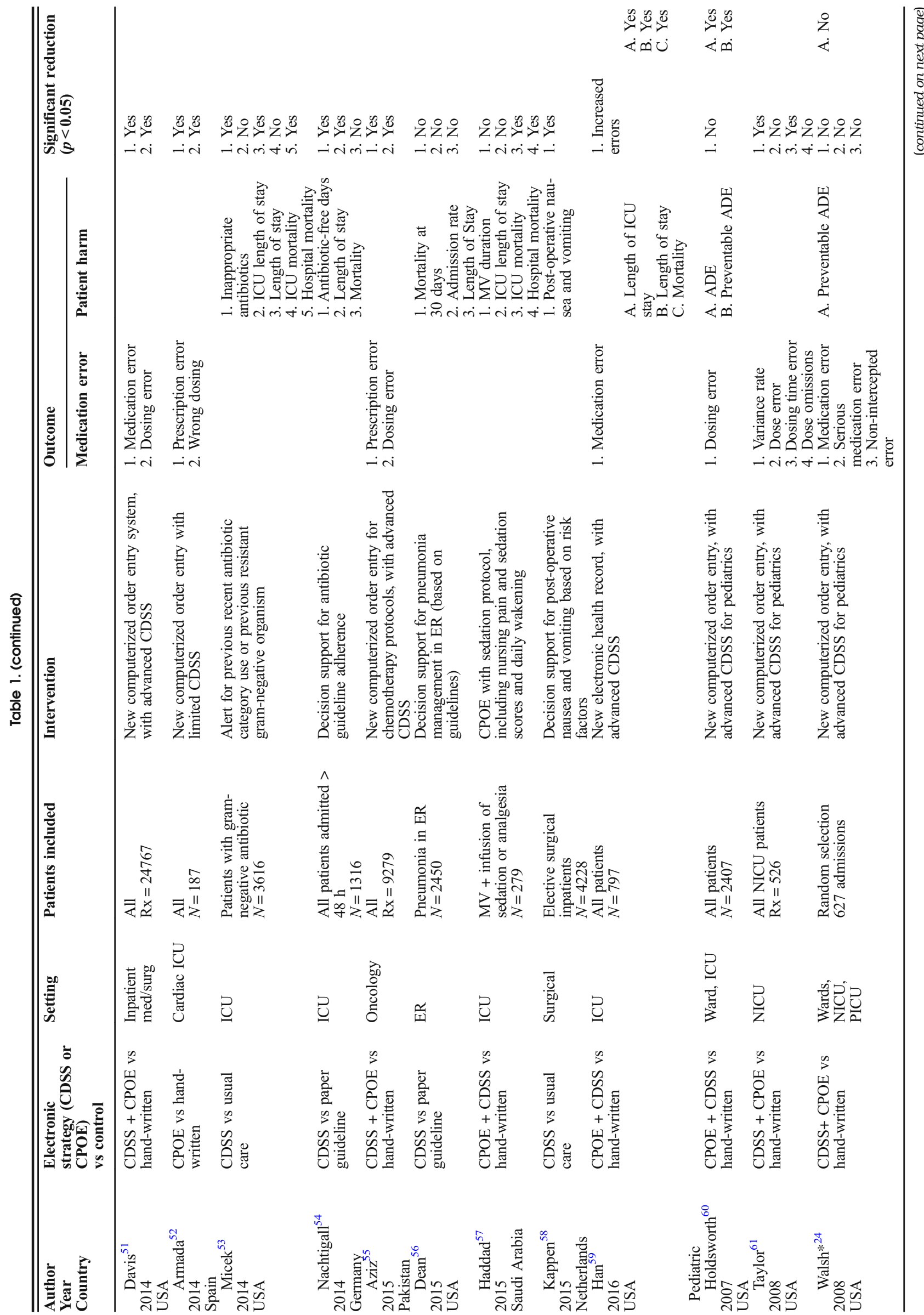




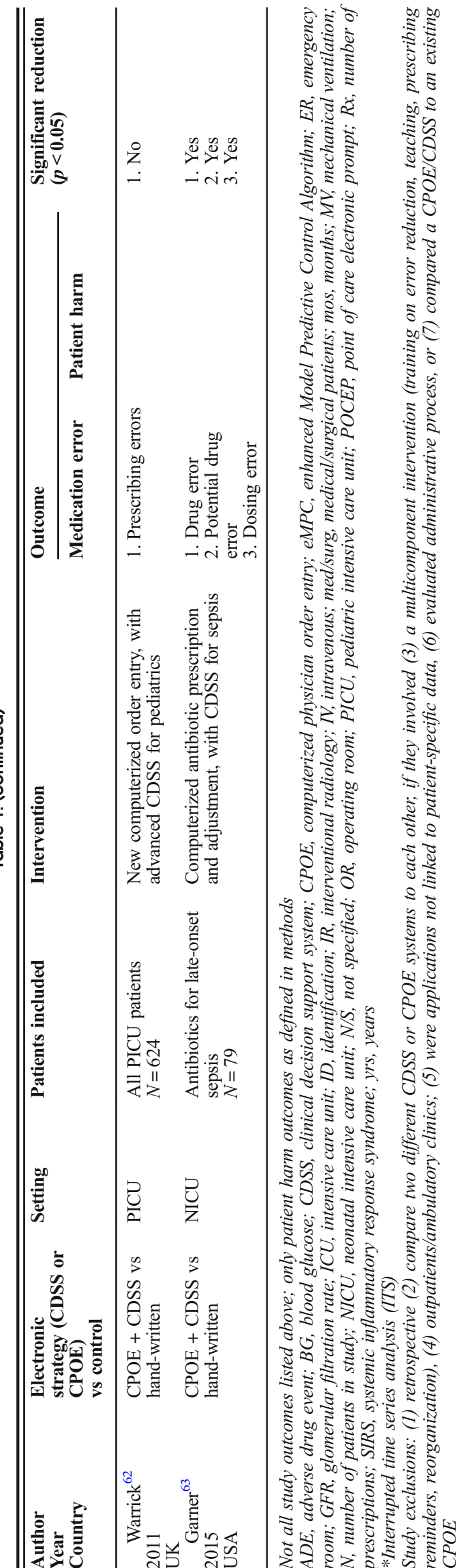

Table 2 Table of Interventions and Outcomes, for Studies Included in the Review ( $N=38$ Included Studies)

\begin{tabular}{lll}
\hline \hline Intervention, $\boldsymbol{N}=\mathbf{3 8}$ & \multicolumn{2}{l}{ Studies with improvement in Outcome } \\
\cline { 2 - 3 } & $\begin{array}{l}\text { Mediation error } \\
(\boldsymbol{N}=\mathbf{1 3})\end{array}$ & $\begin{array}{l}\text { Patient } \mathbf{h a r m}^{\mathrm{a}} \\
(\boldsymbol{N}=\mathbf{2 9})\end{array}$ \\
\hline $\begin{array}{l}\text { CPOE, no CDSS } \\
n=3\end{array}$ & $1 / 1^{50}$ & $0 / 2^{46,47}$ \\
$\begin{array}{l}\text { CPOE }+ \text { limited } \\
\text { CDSS, } n=3\end{array}$ & $2 / 2^{40,52}$ & $1 / 2^{40,57}$ \\
$\begin{array}{l}\text { CPOE + advanced } \\
\text { CDSS, } n=8\end{array}$ & $4 / 8^{24,51,55,59-63}$ & $2 / 3^{24,59,60}$ \\
CDSS alone, $n=24$ & $2 / 2^{42,49}$ & $9 / 22^{27-31,33-38,41,43-}$ \\
& & $45,48,53,54,56,58$ \\
\hline
\end{tabular}

CPOE, computerized physician order entry; CDSS, clinical decision support system

${ }^{a}$ Outcomes listed in Table 1

${ }^{b}$ One study did not specify if CDSS embedded within CPOE (Cartmill)

in children ${ }^{24,62}$ and the other showed an increased overall error rate in adult patients. ${ }^{59}$ Meta-analysis for the effect of electronic prescribing on medication error showed a significant reduction in overall medication errors (RR 0.24 (95\% CI 0.13, $0.46), I^{2} 98 \%, n=11$ ), with high heterogeneity (0 RCT) (Fig. 2a). Meta-regression analysis by year was significant (RR 0.68 (95\% CI 0.56, 0.83), $n=11$ ), with fewer medication errors in more recent publication years (bubble plot, Supplement Figure 2A). Two studies were not included in meta-analysis due to differences in unit of intervention or unit of analysis (Fig. 2a). ${ }^{59,63}$ We rated GRADE quality of evidence as very low overall for the outcome medication error, with asymmetry in the funnel plot (Egger's test, $p=0.003$ ) suggesting publication bias (Supplement Figure 1A).

Dosing errors were reduced in 7 (78\%) of the 9 studies reporting this outcome. All of the studies reporting on dosing error were non-randomized, and compared computerized physician order entry with advanced clinical decision support systems to hand-written prescriptions. Meta-analysis demonstrated a reduction in dosing errors (RR 0.17 (95\% CI 0.08 , $0.38), I^{2} 96 \%, n=9$ ) with electronic versus no electronic strategy, with very high heterogeneity (Fig. 2b). Metaregression by year found fewer errors in more recently published studies (RR 0.73 (95\% CI 0.61, 0.83), $n=9$ ) (bubble plot, Supplement Figure 2B). The reduction in dosing error occurred in adults (RR 0.11 (95\% CI 0.04, 0.32), $I^{2}$ 97\%, $n=$ 6) but was not significant in children (RR 0.55 (95\% CI 0.22 , 1.39), $I^{2} 64 \%, n=3$ ) (data not shown). We rated GRADE quality of evidence for the outcome of dosing error as very low, and the funnel plot shows asymmetry (Egger's test, $p=$ 0.01 ), suggesting possible publication bias (Supplement Figure 1B).

\section{Patient Harm Outcomes}

Twenty-nine $(76 \%)$ studies reported on patient harm outcomes; comprised of ADEs or preventable ADEs $(n=$ 4), ${ }^{24,40,41,60}$ mortality $(n=9), 27,32,35,41,53,54,56,57,59$ length of stay $(n=7),{ }^{32,40,53,54,56,57,59}$ hypoglycemia $(n=8){ }^{28-}$ 
2

CPOE/CDSS Handwritten Risk Ratio

Study or Subgroup Events Total Events Total Weight $\mathrm{M}-\mathrm{H}$, Random, 95\% Cl Year

$\begin{array}{llll}63 & 1195 & 9.8 \% & 0.77[0.53,1.11] \\ 2007\end{array}$

Taylor 2008

Walsh 2008

Van Doormaal 2009

Roberts 2010

Warrick 2011

Zoni 2012

Ali 2013

Davis 2014

Armada 2014

Aziz 2015

Total $(95 \% \mathrm{CI})$

Total events

Heterogeneity: $\mathrm{Tau}^{2}=1.09 ; \mathrm{Chi}^{2}=403.55, \mathrm{df}=10(\mathrm{P}<0.00001) ; \mathrm{I}^{2}=98 \%$

Test for overall effect: $Z=4.27(P<0.0001)$
$0.77[0.53,1.11] 2007$

$0.59[0.39,0.89] 2008$

$1.27[0.92,1.75] 2008$

$0.24[0.23,0.26] 2009$

$0.36[0.22,0.58] 2010$

$0.93[0.47,1.83] 2011$

$0.55[0.32,0.97] 2012$

$0.00[0.00,0.01] 2013$

$0.13[0.09,0.18] 2014$

$0.02[0.01,0.03] 2014 \longrightarrow$

$0.11[0.06,0.21] 2015$

$0.24[0.13,0.46]$

b

CPOE/CDSS Handwritten

Risk Ratio

$\mathrm{M}-\mathrm{H}$, Random, 95\% Cl

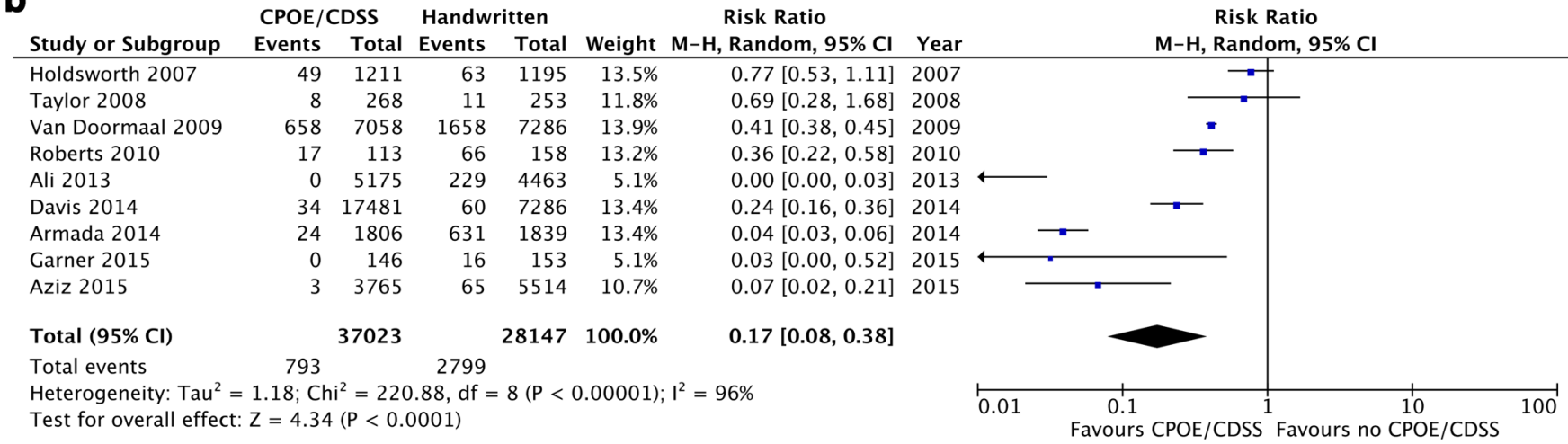

Figure 2 Quantitative analysis using forest plot for the effect of electronic prescribing strategies on risk of a overall medication errors and b dosing errors. a Overall medication errors. b Medication dosing errors. RCT, randomized controlled trial; NRIS, non-randomized

interventional study; M-H, Mantel-Haenszel random effects model. Counts are expressed as events (errors) per total number of prescriptions, except Terrell which is events (errors) per total number of renal dosing alerts. Studies are ordered by calendar year. a Medication error definitions: prescription incomplete (Ali); unintended discrepancies (Zoni); any error in drug ordering, transcribing, dispensing, administration or monitoring (Aziz, Walsh, Van Doormal); proportion of variance between ordered and administered meds (Taylor); any error including drug name, pharmacologic form, dosing, allergy, or interaction (Armada); any pharmacy intervention for wrong dose, drug, patient, drug interaction, allergy, missing medication, or wrong dosage form (Davis); incomplete, insufficient information, illegible, error of prescribing decision or other (Warrick); dosing error (Holdsworth); dosing within $\mathbf{3 0 \%}$ above or below appropriate drug dose from gentamycin, vancomycin, and enoxaparin (Roberts). Garner et al. (NRIS) not included in meta-analysis as number of errors exceeded number of prescriptions (1.1 errors/prescription in control phase). Han et al. (NRIS) not included as medication errors expressed as number of errors per 1000 patient-days. Definition unspecified. b Dosing error definitions: incomplete or wrong dose (Ali); > 10\% over- or underdosing for age and weight (Garner, Taylor); gentamycin/enoxaparin/vancomycin dosing conformity with $30 \%$ of dose (Roberts); error in dosage of dosing figures (Armada); error in strength, frequency, dosage (Aziz, Davis), or length (Van Doormal).

34,36 treatment failure $(n=1),{ }^{27}$ hospitalization and readmission $(n=1),{ }^{37}$ time to therapy $(n=2),{ }^{44,47}$ adequate therapy $(n=1),{ }^{38}$ pain control $(n=2),{ }^{39,46}$ post-operative nausea and vomiting $(n=2),{ }^{48,58}$ and new infection $(n=1) .^{45}$

Four studies reported adverse drug events (ADEs) or preventable ADEs (0 RCT) (Fig. 3a). Three of these studies $(75 \%)$ screened patients for ADEs through pharmacist/ physician review ${ }^{40,41,60}$ and $1(25 \%)$ screened with incident reporting. ${ }^{24}$ Electronic prescribing strategies were associated with reduced ADE (RR 0.52 (95\% CI 0.40, 0.68), $I^{2} 0 \%, n=$ 2), but not preventable ADE (RR 0.55 (95\% CI 0.30, 1.01), $I^{2}$ $78 \%, n=3$ ), versus no electronic strategy. For ADE, the funnel plot did not show significant asymmetry but Egger's test was significant $(p=0.046)$ (Supplement Figure 1C). GRADE quality of evidence was rated as very low.
Nine studies reported mortality (3 RCTs) (Fig. 3b): 7 (78\%) evaluated CDSS alone ( $3 \mathrm{RCTs}$ ) and $2(22 \%)$ evaluated CPOE with advanced CDSS ( 0 RCTs). Overall, there was no effect of computerized prescribing strategies on mortality (RR 0.97 (95\% CI $\left.0.79,1.19), I^{2} 74 \%, n=9\right)$. We rated GRADE quality of evidence overall as low; in the RCTs, quality was rated as high, whereas in the non-randomized studies, we rated GRADE as low with high heterogeneity (Fig. 3b). The funnel plot was symmetrical (Supplement Figure 1D) and Egger's test was not significant.

Length of stay was reported in 7 studies (1 RCT) (Fig. 3c). The forest plot of mean difference (MD) in hospital length of stay (in days) showed reduced length of stay in the one RCT (MD $-6.40(95 \% \mathrm{CI}-13.20,0.40))$, and no significant effect in non-randomized studies (MD $0.0(95 \% \mathrm{CI}-1.25,1.24), I^{2}$ $95 \%, n=6)$ or overall (MD $-0.18(95 \% \mathrm{CI}-1.42,1.05), I^{2}$ 

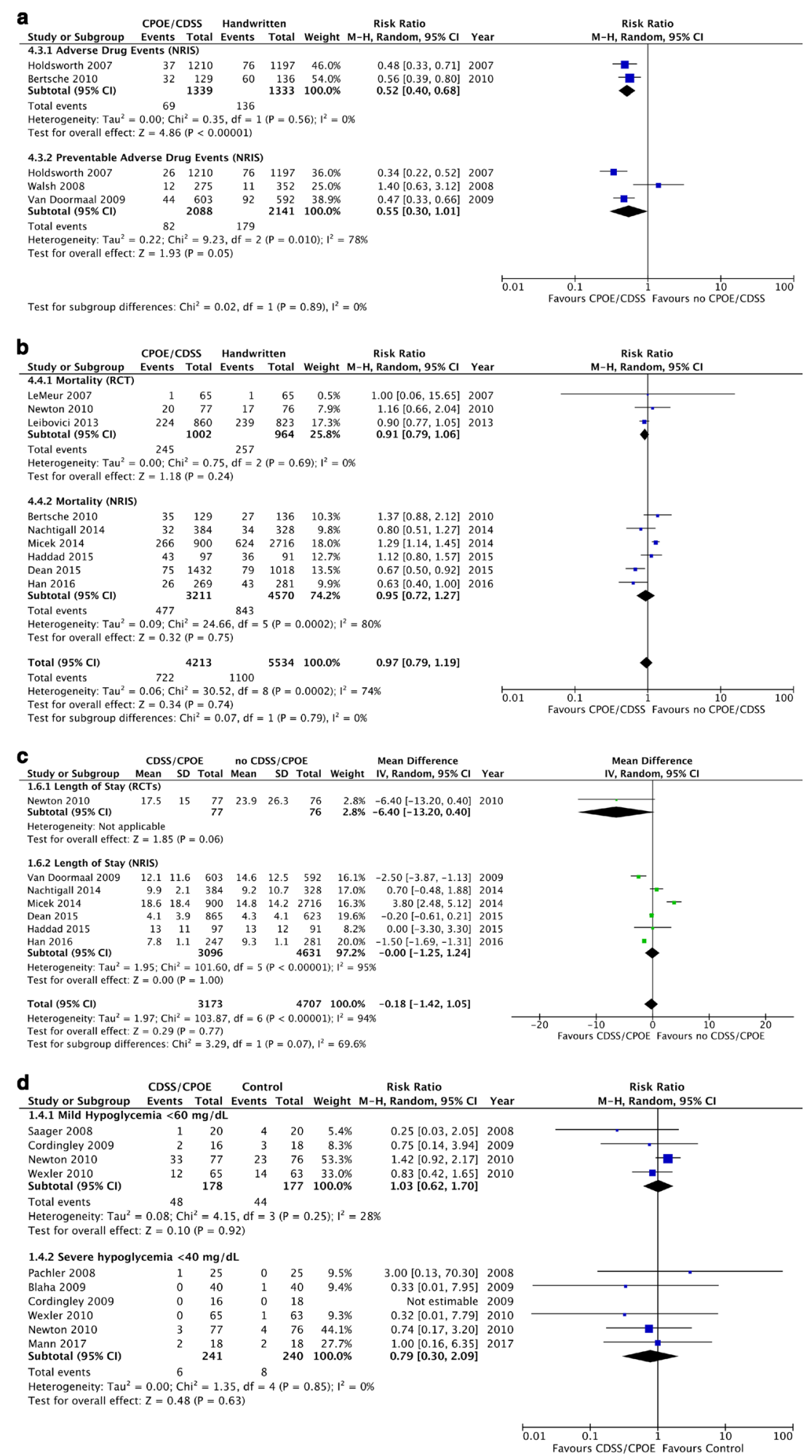

Figure 3 Meta-analysis using forest plot for effect of electronic prescribing strategies on a adverse drug events (ADE), b mortality, $c$ length of hospital stay, and d hypoglycemic events. a Adverse drug events (ADE) and preventable ADE. b Mortality. c Length of stay (in days). d Hypoglycemic events (all RCTs). RCT, randomized controlled trial; NRIS, non-randomized interventional trial; M-H, Mantel-Haenszel random effects model. a Counts are expressed as events (ADE) per total number of patients. Subtotals not pooled due to duplication of studies in each subgroup. b Counts are presented as deaths per number of patients in each group. Mortality is presented as follows: 30-day mortality (Dean),

180-day mortality (Leibocivi), ICU mortality (Haddad), hospital mortality (Micek, Haddad, Newton, Han), overall mortality (Bertsche, Nachtigall at 2 time points), and 12-month mortality (LeMeur). c Counts are mean (SD) length of stay in days in each group, analyzed with mean difference in each group. Studies reported the following: hospital length of stay (Van Doormal, Haddad, Newton, Micek, Dean, Han) and ICU length of stay (Nachtigall). Dean results unadjusted and originally reported as median $(95 \%$ CI) due to skewness. d Counts are patients with hypoglycemic events in each group. All studies of hypoglycemic events are RCTs. Subtotals are not pooled due to study duplication in reporting mild and severe hypoglycemic events. Dumont et al. not included in meta-analysis of hypoglycemic events as data were presented in hypoglycemic events per total glycemic measurements. 
94\%, $n=7)$. We rated GRADE quality of evidence as low overall. The funnel plot did not show asymmetry (Supplement Figure 1E) and Egger's test was not significant.

Eight RCTs evaluated the effect of CDSS for glycemic control (Fig. 3d). Meta-analysis did not demonstrate an effect of automated CDSS on the incidence of mild hypoglycemic episodes ( $<60 \mathrm{mg} / \mathrm{dL})$ (RR 1.03 (95\% CI $0.62-1.70), I^{2} 28 \%$, $n=4)$, or severe hypoglycemic episodes $(<40 \mathrm{mg} / \mathrm{dL})(\mathrm{RR}$ 0.79 (95\% CI $0.30-2.09), I^{2} 0 \%, n=6$ ). One study was not included in meta-analysis due to a difference in units. ${ }^{34} \mathrm{We}$ rated GRADE quality of evidence for hypoglycemia as moderate. The funnel plot did not show asymmetry (Supplement Figure 1F) and Egger's test was not significant for hypoglycemia.

Amongst other outcomes assessed, two studies demonstrated improvement in post-operative nausea and vomiting with electronic prescribing strategies, ${ }^{48,58}$ one study in time to pain control, ${ }^{46}$ and one in frequency of pain assessment and naloxone administration, ${ }^{39}$ compared with no electronic strategy.

\section{Harm Related to Intervention}

Two studies reported an increase in medication errors after electronic intervention. ${ }^{24,59}$ Walsh et al. conducted a time series analysis after CPOE implementation in children and found a decrease in serious non-intercepted medication errors immediately after implementation, followed by a nonsignificant increase in the following season. ${ }^{24} \mathrm{Han}$ et al. found a significant increase in overall medication errors after implementation of an electronic health record with CPOE ( $p=$ 0.002 ) in an adult intensive care unit, which was attributed to errors in delayed drug administrations. ${ }^{59}$

\section{DISCUSSION}

This systematic review and meta-analysis of 38 prospective interventional studies, published since 2007, found that electronic prescribing strategies reduced medication errors, dosing errors, and adverse drug events, compared with no electronic strategy. However, evidence was very low-quality and studies had high risk of bias. Preventable adverse drug events were also reduced by electronic prescribing, although this did not achieve statistical significance. Other patient outcomes including length of stay, mortality, and hypoglycemia were not significantly altered by electronic prescribing. Studies were very heterogeneous; varying in size, settings, interventions, outcomes evaluated, and methodological quality.

This review complements findings of earlier systematic reviews of computerized prescribing strategies versus control that showed improved care processes, ${ }^{8,9}$ adherence to guidelines, ${ }^{64}$ and time to target physiology, ${ }^{7}$ without measurable differences in patient outcomes. More recent systematic reviews have suggested that there may be some effect on patient outcomes, although these are inconsistent. ${ }^{14}$ Nuckols et al. evaluated the effect of CPOE systems and CDSS on errors and adverse drug events in studies published before 2013, and found they reduced preventable adverse drug events, regardless of CDSS sophistication. ${ }^{16}$ A Cochrane Review was updated to 2011 and concluded that computerized advice led to better target physiology of specific medications, decreased thromboembolic events in outpatients, tended to reduce length of hospital stay, but did not change mortality. ${ }^{7}$ The heterogeneity of interventions and outcomes, and predominance of low/very low quality of evidence in our review, are concordant with previous systematic reviews, as was the lack of effect on length of stay or mortality.

In addition to the above, new findings from our metaanalysis support an optimistic view of the potential of computerized systems. We reviewed studies from the last decade with the assumption that advancing prescribing technology may have translated into improvements in patient-related outcomes that were not found in earlier systematic reviews. This assumption was supported by the finding that more recent computerized prescribing strategies have a greater impact on medication and dosing error reduction. In addition, the newer prescribing strategies included in this review had a significant impact on adverse drug events, and possible impact on preventable adverse drug events, suggesting their translation to better clinical outcomes.

The mechanism by which contemporary electronic prescribing strategies reduce medication errors, and adverse drug events is not fully understood. The factors that might contribute to increased error reduction include the following: improvements in ordering and decision support technology, improved electronic health data to which the clinical decision support rules are applied, more sophisticated implementation and widespread adoption of these technologies, or a combination of all these. The reduction in medication and dosing error appears to be related to improved dosing for renal impairment, prescription completeness, and drug-drug interactions. Irrespective of the mechanism of error reduction - now shown in individual studies and meta-analyses spanning several decades, the increased magnitude of error reduction with newer technologies may now be transferred to harm reduction. Further understanding about the contributions of these potential mechanisms of effect may help inform the development of future systems.

There are several limitations to this study. First, the computerized interventions that aid in medical prescribing remain heterogeneous, from order entry without decision support to order entry with advanced decision support. These electronic systems varied greatly in their prescribing function, clinical use, technological development, and target population. This heterogeneity contributes to caution in the interpretation of results. Other systematic reviews on electronic prescribing have also highlighted this heterogeneity, some presenting only quantitative findings without meta-analysis, ${ }^{8,10,13,15}$ while others have combined these heterogeneous interventions to study their effect. ${ }^{7} 16$ Second, reported outcomes were diverse, ranging from prescribing errors to patient symptoms, to 
adverse events, ventilation days, length of stay, and mortality. While electronic strategies may improve physiologic variables and symptomatology, effects on overall outcomes of hospitalization, length of stay, and death have not yet been clearly demonstrated. In addition to the limited quantity of studies per outcome, healthcare organizations and hospitals implement, modify, and study these prescribing strategies differently, contributing to further heterogeneity. Third, the modest number of studies, over a wide variety of hospital patients and settings, limited our ability to conduct further subgroup analysis and sensitivity analysis (with removal of very low-quality studies for example). Finally, the interpretation of findings should be tempered by the limited number of randomized trials in the modern era, of which only $1(9 \%)$ showed clinical benefit from electronic prescribing strategies, and none evaluated medication errors.

An informal review identified a small number of ongoing RCTs evaluating the effects of electronic prescribing on prescribing errors and harm outcomes, such as medication-related falls (Clinicaltrials.gov: NCT03484793, NCT00297609, NCT00818285). Further large randomized trials are needed to increase the quality of the evidence supporting this multibillion-dollar endeavor healthcare expense.

\section{CONCLUSION}

This systematic review of prospective studies found very lowquality evidence that current era electronic prescribing strategies reduced medication errors and adverse drug events in patients, compared with no strategy, in hospitals. The available evidence was heterogeneous, largely non-randomized studies, and provides early data to justify implementation and further evaluation of computerized strategies with higher quality evidence.

Acknowledgments: The authors would like to thank Marla Campbell for creation of the database for data entries, Dr. Prakesh Shah for his valuable input in synthesizing the results, and Dr. Eleanor Pullenayegum for her help with analysis in $R$. In addition, we thank all authors who clarified design for inclusion, and authors Dr. J Han and Dr. N Dean who provided clarification of data.

Corresponding Author: Nadia Roumeliotis, MDCM, MSc; Department of Critical Care MedicineThe Hospital for Sick Children, Toronto, ON, Canada (e-mail: nadia.roumeliotis@gmail.com).

Compliance with Ethical Standards:

Conflict of Interest: N Roumeliotis has doctoral financial support from "Fonds de Recherche Quebec-Santé (FRQS)" as well as from the Canadian Critical Care Trials Group (CCCTG). The remaining authors have disclosed that they do not have any conflicts of interest.

\section{REFERENCES}

1. Crossing the Quality Chiasm. Crossing the Quality Chasm: A New Health System for the 21 st Century. Washington DC: 2001 by the National Academy of Sciences; 2001.

2. Radley DC, Wasserman MR, Olsho LE, Shoemaker SJ, Spranca MD, Bradshaw B. Reduction in medication errors in hospitals due to adoption of computerized provider order entry systems. J Am Med Inform Assoc. 2013;20(3):470-6. https://doi.org/10.1136/amiajnl-2012-001241.

3. Kruse CS, Goetz K. Summary and frequency of barriers to adoption of CPOE in the U.S. J Med Syst. 2015;39(2). https://doi.org/10.1007/ s10916-015-0198-2.

4. Sim I, Gorman P, Greenes RA, Haynes RB, Kaplan B, Lehmann H, et al. Clinical decision support systems for the practice of evidence-based medicine. J Am Med Inform Assoc. 2001;8(6):527-34.

5. Miller K, Mosby D, Capan M, Kowalski R, Ratwani R, Noaiseh Y, et al. Interface, information, interaction: a narrative review of design and functional requirements for clinical decision support. J Am Med Inform Assoc. 2017. https://doi.org/10.1093/jamia/ocx118.

6. Kuperman GJ, Bobb A, Payne TH, Avery AJ, Gandhi TK, Burns G, et al. Medication-related clinical decision support in computerized provider order entry systems: a review. J Am Med Inform Assoc. 2007;14(1):29-40. https://doi.org/10.1197/jamia.M2170.

7. Gillaizeau F, Chan E, Trinquart L, Colombet I, Walton RT, RegeWalther M, et al. Computerized advice on drug dosage to improve prescribing practice. Cochrane Database Syst Rev. 2013;11:CD002894. https://doi.org/10.1002/14651858.CD002894.pub3.

8. Bright TJ, Wong A, Dhurjati R, Bristow E, Bastian L, Coeytaux RR, et al. Effect of clinical decision-support systems: a systematic review. Ann Intern Med. 2012;157(1):29-43. https://doi.org/10.7326/0003-4819157-1-201207030-00450.

9. Garg AX, Adhikari NK, McDonald H, Rosas-Arellano MP, Devereaux PJ, Beyene J, et al. Effects of computerized clinical decision support systems on practitioner performance and patient outcomes: a systematic review. JAMA. 2005;293(10):1223-38. https://doi.org/10.1001/jama. 293.10.1223.

10. Pearson SA, Moxey A, Robertson J, Hains I, Williamson M, Reeve J, et al. Do computerised clinical decision support systems for prescribing change practice? A systematic review of the literature (1990-2007). BMC Health Serv Res. 2009;9:154. https://doi.org/10.1186/1472-6963-9154.

11. Eslami S, Abu-Hanna A, de Keizer NF. Evaluation of outpatient computerized physician medication order entry systems: a systematic review. J Am Med Inform Assoc. 2007;14(4):400-6.

12. Thompson G, O'Horo JC, Pickering BW, Herasevich V. Impact of the electronic medical record on mortality, length of stay, and cost in the hospital and ICU: a systematic review and metaanalysis. Crit Care Med. $2015 ; 43(6): 1276-82$. https://doi.org/10.1097/ccm. 0000000000000948.

13. Wolfstadt JI, Gurwitz JH, Field TS, Lee M, Kalkar S, Wu W, et al. The effect of computerized physician order entry with clinical decision support on the rates of adverse drug events: a systematic review. J Gen Intern Med. 2008;23(4):451-8. https://doi.org/10.1007/s11606-008-0504-5.

14. Ranji SR, Rennke S, Wachter RM. Computerised provider order entry combined with clinical decision support systems to improve medication safety: a narrative review. BMJ Qual Saf. 2014;23(9):773-80. https://doi. org/10.1136/bmjqs-2013-002165.

15. Ammenwerth E, Schnell-Inderst P, Machan C, Siebert U. The effect of electronic prescribing on medication errors and adverse drug events: a systematic review. J Am Med Inform Assoc. 2008;15(5):585-600. https:// doi.org/10.1197/jamia.M2667.

16. Nuckols TK, Smith-Spangler C, Morton SC, Asch SM, Patel VM, Anderson LJ, et al. The effectiveness of computerized order entry at reducing preventable adverse drug events and medication errors in hospital settings: a systematic review and meta-analysis. Syst Rev. 2014;3:56. https://doi.org/10.1186/2046-4053-3-56.

17. Reckmann MH, Westbrook JI, Koh Y, Lo C, Day RO. Does computerized provider order entry reduce prescribing errors for hospital inpatients? A systematic review. J Am Med Inform Assoc. 2009;16(5):613-23. https://doi.org/10.1197/jamia.M3050.

18. Moher D, Liberati A, Tetzlaff J, Altman DG. Preferred reporting items for systematic reviews and meta-analyses: the PRISMA statement. PLoS Med. 2009;6(7):e1000097. https://doi.org/10.1371/journal.pmed. 1000097.

19. PROSPERO. In: International prospective register of systematic reviews. University of York, York. www.crd.york.ac.uk/PROSPERO/display_record.asp?ID=CRD42017055663.

20. Thompson Reuters. EndNote X7.1. USA2014.

21. (EPOC) CEPaOoC. Suggested risk of bias criteria for EPOC reviews. 2017

22. Guyatt G, Oxman AD, Akl EA, Kunz R, Vist G, Brozek J, et al. GRADE guidelines: 1. Introduction-GRADE evidence profiles and summary of findings tables. J Clin Epidemiol. 2011;64(4):383-94. https://doi.org/10. 1016/j.jclinepi.2010.04.026. 
23. GRADEpro. McMaster University: GDT:GRADEpro Guideline Development Tool.; 2015.

24. Walsh KE, Landrigan CP, Adams WG, Vinci RJ, Chessare JB, Cooper MR, et al. Effect of computer order entry on prevention of serious medication errors in hospitalized children. Pediatrics. 2008;121(3):e4217. https://doi.org/10.1542/peds.2007-0220.

25. Review Manager (RevMan) [computer program] Version 5.3 [database on the Internet]. Copenhagen:The Nordic Cochrane Centre, The Cochrane Collaboration 2014

26. RStudio. R Studio Version 1.1.383. Boston RStudio, Inc.; 2009-2017.

27. Le Meur Y, Buchler M, Thierry A, Caillard S, Villemain F, Lavaud S, et al. Individualized mycophenolate mofetil dosing based on drug exposure significantly improves patient outcomes after renal transplantation. Am J Transplant 2007;7(11):2496-503. https://doi.org/10.1111/ j.1600-6143.2007.01983.x.

28. Pachler C, Plank J, Weinhand1 H, Chassin LJ, Wilinska ME, Kulnik R, et al. Tight glycaemic control by an automated algorithm with timevariant sampling in medical ICU patients. Intensive Care Med. 2008;34(7):1224-30. https://doi.org/10.1007/s00134-008-1033-8.

29. Saager L, Collins GL, Burnside B, Tymkew H, Zhang L, Jacobsohn E, et al. A randomized study in diabetic patients undergoing cardiac surgery comparing computer-guided glucose management with a standard sliding scale protocol. J Cardiothorac Vasc Anesth. 2008;22(3):377-82. https://doi.org/10.1053/j.jvca.2007.09.013.

30. Blaha J, Kopecky P, Matias M, Hovorka R, Kunstyr J, Kotulak T, et al. Comparison of three protocols for tight glycemic control in cardiac surgery patients. Diabetes Care. 2009;32(5):757-61. https://doi.org/10. 2337/dc08-1851.

31. Cordingley JJ, Vlasselaers D, Dormand NC, Wouters PJ, Squire SD, Chassin LJ, et al. Intensive insulin therapy: enhanced Model Predictive Control algorithm versus standard care. Intensive Care Med. 2009;35(1):123-8. https://doi.org/10.1007/s00134-008-1236-Z.

32. Newton CA, Smiley D, Bode BW, Kitabchi AE, Davidson PC, Jacobs S, et al. A comparison study of continuous insulin infusion protocols in the medical intensive care unit: computer-guided vs. standard column-based algorithms. J Hosp Med. 2010;5(8):432-7. https://doi.org/10.1002/jhm. 816.

33. Wexler DJ, Shrader P, Burns SM, Cagliero E. Effectiveness of a computerized insulin order template in general medical inpatients with type 2 diabetes: a cluster randomized trial. Diabetes Care. 2010;33(10):2181-3. https://doi.org/10.2337/dc10-0964.

34. Dumont C, Bourguignon C. Effect of a computerized insulin dose calculator on the process of glycemic control. Am J Crit Care. 2012;21(2):106-15. https://doi.org/10.4037/ajcc2012956.

35. Leibovici L, Kariv G, Paul M. Long-term survival in patients included in a randomized controlled trial of treat, a decision support system for antibiotic treatment. J Antimicrob Chemother. 2013;68(11):2664-6. https://doi.org/10.1093/jac/dkt222.

36. Mann EA, Jones JA, Wolf SE, Wade CE. Computer decision support software safely improves glycemic control in the burn intensive care unit: A randomized controlled clinical study. J Burn Care Res. 2011;32(2):24655. https://doi.org/10.1097/BCR.0b013e31820aaebf.

37. Geurts D, de Vos-Kerkhof E, Polinder S, Steyerberg E, van der Lei J, Moll $\mathbf{H}$, et al. Implementation of clinical decision support in young children with acute gastroenteritis: a randomized controlled trial at the emergency department. 2017;1.

38. Rohrig R, Niczko EJ, Beutefuhr $\mathbf{H}$, Bottger S, Klasen $\mathbf{J}$, Fussle $\mathbf{R}$ et al. Examination of computer assisted prescribing of an initial calculated antibiotic treatment. Stud Health Technol Inform. 2008; 136:63-8.

39. Okon TR, Lutz PS, Liang H. Improved pain resolution in hospitalized patients through targeting of pain mismanagement as medical error. J Pain Symptom Manag. 2009;37(6):1039-49. https://doi.org/10.1016/j. jpainsymman.2008.06.009.

40. van Doormaal JE, van den Bemt PM, Zaal RJ, Egberts AC, Lenderink BW, Kosterink JG, et al. The influence that electronic prescribing has on medication errors and preventable adverse drug events: an interrupted time-series study. J Am Med Inform Assoc. 2009;16(6):816-25. https:// doi.org/10.1197/jamia.M3099.

41. Bertsche T, Pfaff J, Schiller P, Kaltschmidt J, Pruszydlo MG, Stremmel W, et al. Prevention of adverse drug reactions in intensive care patients by personal intervention based on an electronic clinical decision support system. Intensive Care Med. 2010;36(4):665-72. https://doi.org/10.1007/s00134-010-1778-8

42. Roberts GW, Farmer CJ, Cheney PC, Govis SM, Belcher TW, Walsh SA, et al. Clinical decision support implemented with academic detailing improves prescribing of key renally cleared drugs in the hospital setting. $J$ Am Med Inform Assoc. 2010;17(3):308-12. https://doi.org/10.1136/ jamia.2009.001537.

43. Tafelski S, Nachtigall I, Deja M, Tamarkin A, Trefzer T, Halle E, et al. Computer-assisted decision support for changing practice in severe sepsis and septic shock. J Int Med Res. 2010;38(5):1605-16.

44. Nelson JL, Smith BL, Jared JD, Younger JG. Prospective trial of realtime electronic surveillance to expedite early care of severe sepsis. Ann Emerg Med. 2011;57(5):500-4. https://doi.org/10.1016/j. annemergmed.2010.12.008.

45. Schwann NM, Bretz KA, Eid S, Burger T, Fry D, Ackler F, et al. Pointof-care electronic prompts: an effective means of increasing compliance, demonstrating quality, and improving outcome. Anesth Analg. 2011;113(4):869-76. https://doi.org/10.1213/ANE. Ob013e318227b511.

46. Blankenship JF, Rogers L, White J, Carey A, Fosnocht D, Hopkins C, et al. Prospective evaluation of the treatment of pain in the ED using computerized physician order entry. Am J Emerg Med. 2012;30(8):16136. https://doi.org/10.1016/j.ajem.2011.11.003.

47. Cartmill RS, Walker JM, Blosky MA, Brown RL, Djurkovic S, Dunham DB, et al. Impact of electronic order management on the timeliness of antibiotic administration in critical care patients. Int $\mathrm{J}$ Med Inform. 2012;81(11):782-91. https://doi.org/10.1016/j.ijmedinf.2012.07.011.

48. Kooij FO, Vos N, Siebenga P, Klok T, Hollmann MW, Kal JE. Automated reminders decrease postoperative nausea and vomiting incidence in a general surgical population. $\mathrm{Br} \mathrm{J}$ Anaesth. 2012;108(6):961-5. https://doi.org/10.1093/bja/aes024.

49. Zoni AC, Duran Garcia ME, Jimenez Munoz AB, Salomon Perez R, Martin P, Herranz AA. The impact of medication reconciliation program at admission in an internal medicine department. Eur J Intern Med. 2012;23(8):696-700. https://doi.org/10.1016/j.ejim.2012.08.013.

50. Ali J, Barrow L, Vuylsteke A. The impact of computerised physician order entry on prescribing practices in a cardiothoracic intensive care unit. Anaesthesia. 2010;65(2):119-23. https://doi.org/10.1111/j.13652044.2009.06134.x.

51. Davis L, Brunetti L, Lee EK, Yoon N, Cho SH, Suh DC. Effects of computerized physician order entry on medication turnaround time and orders requiring pharmacist intervention. Res Soc Adm Pharm. 2014;10(5):756-67. https://doi.org/10.1016/j.sapharm.2013.11.004.

52. Armada ER, Villamanan E, Lopez-de-Sa E, Rosillo S, Rey-Blas JR, Testillano ML, et al. Computerized physician order entry in the cardiac intensive care unit: effects on prescription errors and workflow conditions. J Crit Care. 2014;29(2):188-93. https://doi.org/10.1016/j.jcrc. 2013.10.016.

53. Micek ST, Heard KM, Gowan M, Kollef MH. Identifying critically ill patients at risk for inappropriate antibiotic therapy: a pilot study of a point-of-care decision support alert. Crit Care Med. 2014;42(8):1832-8. https://doi.org/10.1097/CCM.0000000000000337.

54. Nachtigall I, Tafelski S, Deja M, Halle E, Grebe MC, Tamarkin A, et al. Long-term effect of computer-assisted decision support for antibiotic treatment in critically ill patients: A prospective 'before/after' cohort study. BMJ Open. 2014;4 (12) (no pagination)(e005370). https://doi.org/ 10.1136/bmjopen-2014-005370.

55. Aziz MT, Ur-Rehman T, Qureshi S, Bukhari NI. Reduction in chemotherapy order errors with computerised physician order entry and clinical decision support systems. Health Inf Manage J. 2015;44(3):13-22.

56. Dean NC, Jones BE, Jones JP, Ferraro JP, Post HB, Aronsky D, et al. Impact of an electronic clinical decision support tool for emergency department patients with pneumonia. Ann Emerg Med. 2015;66(5):51120. https://doi.org/10.1016/j.annemergmed.2015.02.003.

57. Haddad SH, Gonzales CB, Deeb AM, Tamim HM, AlDawood AS, Al Babtain I, et al. Computerized physician order entry of a sedation protocol is not associated with improved sedation practice or outcomes in critically ill patients. BMC Anesthesiol. 2015;15:177. https://doi.org/10. 1186/s12871-015-0161-2

58. Kappen TH, Vergouwe Y, VanWolfswinkel L, Kalkman CJ, Moons KGM, Van Klei WA. Impact of adding therapeutic recommendations to risk assessments from a prediction model for postoperative nausea and vomiting. Br J Anaesth. 2015;114(2):252-60. https://doi.org/10.1093/ bja/aeu321.

59. Han JE, Rabinovich M, Abraham P, Satyanarayana P, Liao TV, Udoji TN, et al. Effect of electronic health record implementation in critical care on survival and medication errors. Am J Med Sci. 2016;351(6):576-81. https://doi.org/10.1016/j.amjms.2016.01.026

60. Holdsworth MT, Fichtl RE, Raisch DW, Hewryk A, Behta M, MendezRico E, et al. Impact of computerized prescriber order entry on the 
incidence of adverse drug events in pediatric inpatients. Pediatrics. 2007; 120(5): 1058-66

61. Taylor JA, Loan LA, Kamara J, Blackburn S, Whitney D. Medication administration variances before and after implementation of computerized physician order entry in a neonatal intensive care unit. Pediatrics. 2008;121(1):123-8. https://doi.org/10.1542/peds.2007-0919.

62. Warrick C, Naik H, Avis S, Fletcher P, Franklin BD, Inwald D. A clinical information system reduces medication errors in paediatric intensive care. Intensive Care Med. 2011;37(4):691-4. https://doi.org/10.1007/ s00134-010-2126-8.

63. Garner SS, Cox TH, Hill EG, Irving MG, Bissinger RL, Annibale DJ. Prospective, controlled study of an intervention to reduce errors in neonatal antibiotic orders. J Perinatol. 2015;35(8):631-5. https://doi. org/10.1038/jp.2015.20.

64. Eslami S, de Keizer NF, Abu-Hanna A. The impact of computerized physician medication order entry in hospitalized patients-a systematic review. Int J Med Inf. 2008;77(6):365-76.

Publisher's Note: Springer Nature remains neutral with regard to jurisdictional claims in published maps and institutional affiliations. 